\title{
Smoking in movies: when will the saga end?
}

\section{Jonathan M Samet}

In the 1930s, Edward Bernays, the originator of cigarette marketing strategies still in use today, recognised the marketing power of encouraging the use of cigarettes in film, and cigarettes were made an important prop in movies. ${ }^{12}$ This strategy stuck. Standardised assessments of movies' content over a time period extending from the 1930s to the present day document that cigarettes and cigarette smoking have been commonly portrayed in movies, possibly at a frequency that exceeds actual use patterns. ${ }^{2}$ Concern about smoking in movies is not new but only recently, however, has research been carried out to assess if seeing smoking in movies increases risk for initiation of smoking. ${ }^{3}$ The most definitive evidence comes from cohort studies that prospectively assess risk for initiation in association with the profile of movies previously viewed. These studies are not affected by the temporal ambiguity that clouds cross-sectional studies, but even prospectively determined associations might partially reflect a factor-for example, risk-taking behaviour, that affects both movie choices and likelihood of initiating smoking.

Mounting experimental and observational evidence now shows that smoking in movies is associated with initiation of smoking by youths; a 2008 review in the National Cancer Institute Monograph 19, The Role of Media in Promoting and Reducing Tobacco Use, concluded: "The total weight of evidence from cross-sectional, longitudinal, and experimental studies, combined with the high theoretical plausibility from the perspective of social influences, indicates a causal relationship between exposure to movie smoking depictions and youth smoking initiation". ${ }^{2}$ This causal conclusion brings the possibility of reduction of initiation by reducing exposure of youths to seeing smoking in movies. Estimates of movie-smoking attributable initiation and the eventual burden of disease suggest that the benefits of

Correspondence to Dr Jonathan M Samet, Department of Preventive Medicine, Keck School of Medicine, USC Institute for Global Health, University of Southern California, 1441 Eastlake Avenue, Room 4436, Los Angeles, CA 90089, USA; jsamet@usc.edu reducing exposure to smoking in movies could be substantial. ${ }^{4}$ For example, TitusErnstoff and colleagues ${ }^{5}$ estimated that $35 \%$ of smoking initiation is attributable to movie smoking exposure, based on a cohort study in the US states of New Hampshire and Vermont. Such estimates are based on a counterfactual (comparison) scenario of no smoking at all in moviesnot achievable at present-and they should be extended to other populations with great caution.

This issue of Tobacco Control includes four articles that offer findings relevant to smoking in movies, to its consequences and to countering its effects. Jamieson and Romer ${ }^{6}$ describe the 'tobacco content' of smoking in movies from 1950 through 2006. About 20 such assessments have been previously reported with variable findings as to the frequency and temporal trends of smoking content. The methods have differed across the studies as have the time periods covered. Consequently, the report by Jamieson and Romer is useful for its standardised assessment across a critical time window that began with the recognition of the risks of smoking and that extended across a period of steadily declining smoking. The main finding is that tobacco content parallels adult cigarette consumption in the USA across this period. The decline is 'good news', although the persistence of this causal factor for initiation in widely viewed movies implies that some children are initiating smoking because of this exposure.

Anderson and colleagues ${ }^{7}$ characterise exposure of youths in the UK to smoking in movies over the period 2001-2006. In the UK, the movie rating scheme allows greater youth access to films that would be ' $R$ ' rated in the USA, and consequently youths in the UK have substantially greater exposure than in the USA, as would those in any country that rates movies less conservatively than the USA. On the assumption of a dose-response relation between smoking exposure and risk for initiation, greater exposure at the population level implies a greater contribution to initiation, leading to the question as to whether the moving rating scheme in the UK should be altered.
The determination that smoking caused lung cancer and other diseases, first made in the 1950 s and $1960 \mathrm{~s},{ }^{1}$ led to a broad array of actions, still continuing, to control tobacco use. Should the causal finding with regard to exposure to smoking in movies and youth initiation also be the basis for action? The World Health Organization ${ }^{8}$ has called for action, noting that Article 13 of the Framework Convention on Tobacco Control (FCTC) covers smoking in movies. The options for action range from parental restrictions of the movies viewed by their children to voluntary or regulatory measures to control smoking content and to consider smoking in rating movies.

One strategy is to counter the effect of viewing smoking in movies by antismoking messages. Experimental approaches have been used to assess whether antismoking spots, shown before smoking-containing movies, are an 'antidote'. For initiation, studies show that there can be an immediate countering of the imagery of smoking in movies by viewing an antismoking advertisement before a movie with smoking (see, eg, Edwards et al ${ }^{910}$ ). In this issue, the report by Harakeh et al ${ }^{11}$ shows that in an experimental context viewing antismoking ads has a short-term benefit for smokers, as they view movies that portray smoking. Whether there is a lasting effect was not assessed in the design and movies are now viewed in formats-for example, DVDs or online, that complicate inclusion of antismoking materials.

In the USA, Smoke Free Movies, led by Stanton Glantz at the University of California San Francisco and supported by the American Legacy Foundation, the Robert Wood Johnson Foundation and other funders, has waged a vigorous campaign to reduce smoking in movies. ${ }^{12}$ Is this campaign supported by the public, particularly the call for an ' $R$ ' rating for films with smoking? The findings of a survey conducted in 2004-2006 indicated general support for limiting smoking in movies, including use of the ' $R$ ' rating. ${ }^{13}$ In data from a 2003 survey, Blake et al $^{14}$ in this issue find general support among a national US sample for limiting exposure to smoking in movies and including antismoking public service announcements before showing movies with smoking. Respondents were split, however, with regard to the use of the ' $\mathrm{R}$ ' rating. Attitudes towards smoking in movies varied with smoking status and exposure to anti-tobacco advertising.

Bernays' recognition of the power of imagery in movies is now confirmed by health researchers. The papers in this issue of Tobacco Control add to our understanding 
of smoking in movies, documenting its earlier rise and recent fall, the scope of exposure in the UK, possible countering measures, and public support for intervention. Most importantly, the evidence from these and other studies continues to support the case that exposure to smoking in movies is one specifically remediable determinant of initiation, and a determinant with global reach.

Competing interests None.

Provenance and peer review Commissioned; externally peer reviewed.

Tobacco Control 2010;19:173-174.

doi:10.1136/tc.2010.037358

\section{REFERENCES}

1. Brandt AM. The cigarette century: the rise, fall, and deadly persistence of the product that defined America. New York: Basic Books, 2007.
2. National Cancer Institute. The role of the media in promoting and reducing tobacco use. Tobacco control monograph no. 19. Bethesda, MD: U.S. Department of Health and Human Services, National Institutes of Health, National Cancer Institute, 2008.

3. Chapman S, Davis RM. Smoking in movies: is it a problem? Tob Control 1997;6:269-71.

4. Glantz SA. Smoke free movies: health impacts. http://www.smokefreemovies.ucsf.edu/problem/ health impacts.html (accessed 9 Apr 2010).

5. Titus-Ërnstoff L, Dalton MA, Adachi-Mejia AM, et al. Longitudinal study of viewing smoking in movies and initiation of smoking by children. Pediatrics 2008;121:15-21.

6. Jamieson PE, Romer D. Trends in US movie portrayal since 1950: an historical analysis. Tob Control 2010;19:179-84.

7. Anderson SJ, Millett C, Polansky JR, et al. Exposure to smoking in movies among British adolescents 2001-2006. Tob Control 2010;19:197-200.

8. World Health Organization. Smoke-free movies. from evidence to action. Geneva: WHO, 2009.

9. Edwards C, Oakes W, Bull D. Out of the smokescreen II: will an advertisement targeting the tobacco industry affect young people's perception of smoking in movies and their intention to smoke? Tob Control 2007; 16:177-81.

10. Edwards CA, Harris WC, Cook DR, et al. Out of the Smokescreen: does an anti-smoking advertisement affect young women's perception of smoking in movies and their intention to smoke? Tob Control 2004:13:277-82.

11. Harakeh Z, Engels RCME, Vohs K, et al. Exposure to movie smoking, antismoking ads, and smoking intensity: an experimental study with a factorial design. Tob Control 2010;19:185-90.

12. Glantz SA. Smoke free movies. http://www. smokefreemovies.ucsf.edu/index.html laccessed 9 Apr 2010).

13. McMillen RC, Tanski S, Winickoff J, et al. Attitudes about smoking in the movies. Starkville, MS: The National Social Climate Survey of Tobacco Control 2007. http://www.socialclimate.org/pdf/smokingattitudes-movies.pdf (accessed 9 Apr 2010).

14. Blake KD, Viswanath K, Blendon RJ, et al. The role of reported tobacco-specific media exposure on adult attitudes toward proposed policies to limit the portrayal of smoking in movies. Tob Control 2010;19:191-6. 